SECTION 31. Economic studies, Finance, innovation.

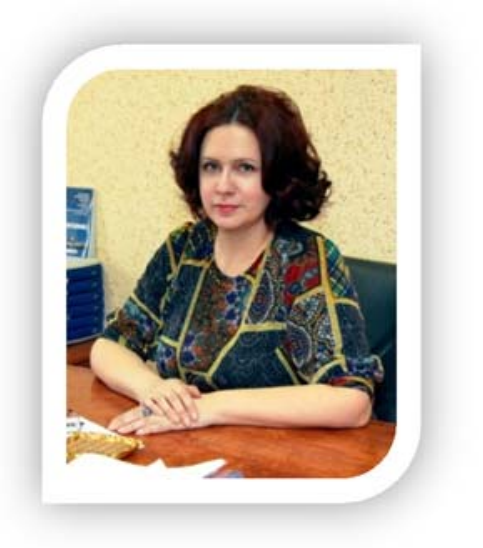

Solonenko Anna Aleksandrovna

candidate of Economic Sciences

Associate Professor Department of Accounting,

Analysis and Audit

Astrakhan State Technical University

Astrakhan, Russia

\title{
CLASSIFICATION OF ACCOUNTING SYSTEMS WITH THE POSITION OF THE EVOLUTIONARY DEVELOPMENT OF ACCOUNTING
}

Abstract: Description of the unified accounting system of the group of interrelated organizations as an organized set of types of accounting, coordinated by the unity of the factors of production resulting information to various users and a common database enables you to expand the conceptual apparatus of the theory of accounting concepts: «unified accounting system of a group of interrelated organizations», and «Type», «Class», «Family» of accounting systems.

Key words: differentiation of accounting, account type system.

\section{КЛАССИФИКАЦИЯ УЧЕТНЫХ СИСТЕМ С ПОЗИЦИИ ЭВОЛЮЦИОННОГО РАЗВИТИЯ БУХГАЛТЕРСКОГО УЧЕТА}

Аннотация: Описание единой учетной системь группь взаимосвязанных организаций как организованной совокупности видов бухгалтерского учета, координированных единством факторов производства результатной информачии для различных пользователей и общей базой данных, позволяет расширить понятийньй аппарат теории бухгалтерского учета понятиями: «Единая учетная система группь взаимосвязанных организаџий», а также «Тип», «Класс», «Семейство» учетных систем.

Ключевые слова: дифференциачия бухгалтерского учета, тип учетной системы.

На современном этапе эволюционного развития бухгалтерский учет характеризуется универсальностью и высокой степенью адаптивности к образованию корпоративной собственности, созданию крупных национальных и транснациональных корпораций. Результатом генезиса практики корпоративного управления является активизация усилий в направлении формирования методологической основы организации общего учетного процесса в группах взаимосвязанных организаций.

При построении понятийного аппарата исследований в данной области предлагается рассматривать «учетную систему» как базовую категорию, представляющую собой процессную информационную систему, состоящую из множества составных элементов, являющихся также системами, но уже низшего ранга, на входе в которую находится первичная информация, а на выходе - результатная учетная информация для определенных пользователей. 
На макроуровне национальную систему бухгалтерского учета следует рассматривать как соответствующую бухгалтерской парадигме совокупность методологии ведения учета и технологии учетного процесса, используемых в рамках национальных стандартов (положений) бухгалтерского учета.

Формируя учетную систему субъекта экономики, необходимо учитывать в какой национальной системе бухгалтерского учета она будет работать, при этом в современных условиях происходит абстрагирование от конкретной организации, развиваются подходы, принципы и методы, универсальные для взаимосвязанных субъектов хозяйствования.

Стремительный рост слияний, поглощений, объединений ранее независимых организаций, осуществляющих деятельность на межрегиональном, международном уровнях, обуславливает необходимость формирования единой учетной системы группы взаимосвязанных и взаимозависимых хозяйствующих субъектов.

Единая учетная система группы - это продукт современного этапа эволюционного развития бухгалтерского учета. Бухгалтерский учет призван отражать и контролировать разнохарактерные экономические процессы, явления, информационные факты во всем их многообразии, удовлетворяя конкретные цели различных пользователей, следовательно, возникает необходимость во многих учетных системах разной сложности, информационной вместимости и специфичности.

С позиции эволюционного подхода к развитию учетных систем можно выделить четыре основные иерархические единицы (тип-класс-семейство-вид) в систематизации учетного множества (табл.1).

Для определения исторических типов учетных систем в качестве наиболее важного признака их структурного многообразия определен способ учетной регистрации.

Tunbl учетных систем различаются по способу регистрации фактов хозяйственной жизни. В соответствии с избранными признаками (униграфическая, диграфическая и полиграфическая парадигма) выделены три исторических типа: простая инвентарная система, учетная информационная система и интегрированная учетная система.

Таблица 1

Классификация учетных систем

\begin{tabular}{|c|c|c|c|c|}
\hline $\begin{array}{l}\text { № } \\
\Pi / \Pi\end{array}$ & $\begin{array}{c}\text { Уровни } \\
\text { систематизации }\end{array}$ & $\begin{array}{c}\text { Признак } \\
\text { систематизации }\end{array}$ & $\begin{array}{c}\text { Характеристика } \\
\text { признака } \\
\text { систематизации }\end{array}$ & $\begin{array}{c}\text { Субординация } \\
\text { учетных систем и их } \\
\text { структурных } \\
\text { элементов }\end{array}$ \\
\hline 1. & ТИПЫ & $\begin{array}{l}\text { Методологические } \\
\text { парадигмы: способ } \\
\text { регистрации } \\
\text { фактов } \\
\text { хозяйственной } \\
\text { жизни }\end{array}$ & $\begin{array}{l}\text { Униграфический } \\
\text { Диграфический } \\
\text { Полиграфический }\end{array}$ & $\begin{array}{l}\text { Простая инвентарная } \\
\text { система } \\
\text { Учетная } \\
\text { информационная } \\
\text { система } \\
\text { Интегрированная } \\
\text { учетная система }\end{array}$ \\
\hline 2. & КЛАССЫ & $\begin{array}{l}\text { Уровни строения } \\
\text { глобальной } \\
\text { экономики }\end{array}$ & $\begin{array}{l}\text { Макроуровень } \\
\text { Мезоуровень } \\
\text { Микроуровень }\end{array}$ & $\begin{array}{l}\text { Национальная } \\
\text { система } \\
\text { бухгалтерского учета } \\
\text { Единая } \quad \text { учетная } \\
\text { система группы } \\
\text { Учетная } \quad \text { система } \\
\text { организации } \quad \text { и ее }\end{array}$ \\
\hline
\end{tabular}




\begin{tabular}{|c|c|c|c|c|}
\hline & & & & $\begin{array}{l}\text { структурных } \\
\text { подразделений }\end{array}$ \\
\hline 3. & СЕМЕЙСТВА & $\begin{array}{l}\text { Специфика } \\
\text { субъектов учета и } \\
\text { методологии } \\
\text { отраслевых } \\
\text { стандартов учета }\end{array}$ & $\begin{array}{l}\text { Сектор } \\
\text { экономики } \\
\text { Виды } \\
\text { экономической } \\
\text { деятельности }\end{array}$ & $\begin{array}{l}\text { Учет в коммерческих } \\
\text { организациях } \\
\text { Бюджетный учет } \\
\text { Учет } \\
\text { промышленности, } \\
\text { сельском хозяйстве, } \\
\text { торговле, страховых } \\
\text { организациях, банках } \\
\text { и т.д. }\end{array}$ \\
\hline 4. & ВИДЫ $^{1}$ & $\begin{array}{l}\text { Целеполагание } \\
\text { пользователей } \\
\text { производителей } \\
\text { учетной } \\
\text { информации }\end{array}$ & $\begin{array}{l}\text { Контрагенты } \\
\text { Налоговые } \\
\text { органы страны } \\
\text { Государственные } \\
\text { органы, органы } \\
\text { местного } \\
\text { самоуправления } \\
\text { Собственники и } \\
\text { управляющие } \\
\text { Социально- } \\
\text { ответственный } \\
\text { бизнес } \\
\text { общество в целом } \\
\text { Природоохранные } \\
\text { институты } \\
\text { общество и } \\
\text { Общественно- } \\
\text { значимые } \\
\text { компании }\end{array}$ & $\begin{array}{l}\text { Финансовый учет } \\
\text { Налоговый учет } \\
\text { Статистический учет } \\
\text { Управленческий учет } \\
\text { Социальный учет }\end{array}$ \\
\hline
\end{tabular}

Класс учетной системы характеризуется признаками, определяемыми уровнями строения глобальной экономики. С этой позиции выделены микроуровень (учетная система организации), мезоуровень (единая учетная система группы) и макроуровень (национальная система бухгалтерского учета) архитектуры построения учетных систем.

Семейства учетного множества заданы спецификой секторов экономики и видов экономической деятельности, определяющих отраслевые стандарты учета. Это учет в государственных (муниципальных) учреждениях и учет в коммерческих организациях, а также по видам экономической деятельности: учет в промышленности, сельском хозяйстве, торговле, банках, страховых организациях и т.д.

Таким образом, для учетных систем характерна множественность состояний, динамизм, альтернативность эволюции. Названные признаки остаются открытыми для уточнения и дополнения. В частности, в каждом исследуемом историческом периоде может существовать учет различной степени зрелости. Так, до сих пор сохраняется тип

${ }^{1}$ Процесс дифференциации видов учета непрерывен 
простого учета в домашних хозяйствах, отдельных малых предприятиях, $\mathrm{y}$ индивидуальных предпринимателей, тогда как среда среднего и крупного бизнеса порождает все новые зарождающиеся, развивающиеся и развитые виды учета (финансовый, управленческий, налоговый, консолидированный учет, учет по международным стандартам, социальный, экологический и т.д.).

Основными структурными подсистемами учетной системы субъекта экономики являются виды учета. Вид учета обладает специфической целью и методологией, выполняет функции, определяемые целеполаганием пользователей и производителей результатной информации, сохраняет свою автономию в учетной системе и имеет собственную эволюционную траекторию. Каждый вид учета регулируется особыми правилами и требует специальных знаний.

Любая видовая классификация учетного множества остается субъективной, вызывает противоречивые суждения и зависит от целей исследователя. Однако закономерный процесс эволюционного развития бухгалтерского учета характеризуется обменом экономической информации между видами учета и установлением новых взаимосвязей между ними.

Предлагается деление видов учета на три уровня: 1) обязательные для применения виды учета (финансовый, налоговый, статистический и консолидированный); 2) виды учета, требующие специальных знаний, имеющие специфические цель и методологию, но не обязательные для применения (управленческий, социальный и экологический); 3) направления в теории и практике бухгалтерского учета, позволяющие повысить продуктивность научных исследований (актуарный, стратегический и проч.).

Единая учетная система группы объединяет, прежде всего, подсистемы финансового, управленческого, налогового и консолидированного учета. Возрастающие информационные потребности управляющих различных уровней стимулируют возникновение и развитие новых функций бухгалтерского учета. Функциональная дифференциация видов бухгалтерского учета перерастает в структурную в результате эволюции совокупности организационных и методологических признаков. Завершающим пунктом каждого этапа структурной дифференциации учетного множества является сформированная теория каждого автономного вида бухгалтерского учета, включающая цель учетного наблюдения, предмет и совокупность специфических приемов отображения объектов, образующих метод.

Дифференциация видов бухгалтерского учета, определяется различными признаками: эволюционным (по историческому типу, этапу развития бухгалтерского учета, уровню строения глобальной экономики и т.д.), прагматическим (по целеполаганию пользователей учетной информации и ее производителей), предметным (по парадигме учета), структурно-функциональным (по выделению в системе структурных составляющих и их роли относительно друг друга) [1], аналитическим (по типу анализа), методологическим (по способу познания). К критериям дифференциации видов бухгалтерского учета следует отнести ориентацию современной учетной системы на принципиальное улучшение информационного сервиса, предоставляемого пользователям учетной информации в условиях адаптации экономических субъектов к внешним факторам и изменениям внутренней структуры группы.

Эволюционный процесс развития учетных систем характеризуется горизонтальным обменом экономической информацией между видами бухгалтерского учета и установлением за счет процесса интеграции новых взаимосвязей между ними. Чрезмерная дифференциация приводит с организаторских позиций к возрастанию 
дублирующей излишней информации, а с методологической точки зрения, к рассеиванию интегральных свойств исследуемых объектов бухгалтерского учета.

Идея интеграционного взаимодействия информационных потоков в бухгалтерском учете является предметом интенсивных теоретических исследований и практических разработок на протяжении не одного десятка лет. В настоящее время процессы объединения различных учетных систем обуславливаются не столько возможностями развития средств связи, передачи данных и вычислительной техники, сколько стремительным ростом процессов слияний и поглощений, вследствие естественных интеграционных процессов концентрации производства, капитала и реструктуризации экономики. Под интеграцией нами понимается процесс объединения учетных систем взаимосвязанных организаций в единую учетную систему.

Расширение бизнеса посредством интегрирования с другими субъектами хозяйствования делает необходимым формирование комплекса обобщенной, детализированной и релевантной информации, раскрывающей итоги деятельности группы при оптимизации сроков еe представления для заинтересованных пользователей с применением новейших программных продуктов учета, как в материнской компании, так и в территориально удаленных подразделениях.

Финансовый, управленческий, налоговый и консолидированный виды учета, интегрируемые в единой учетной системе группы, имеют многообразные цели, предмет, методы и предназначены для разных пользователей информации. Интеграционные процессы не стирают методологических отличий между видами бухгалтерского учета, а взаимодополняют их при решении конкретных прикладных задач в учетной практике.

\section{Список литературы:}

1. Перекрестова, Л.В. Эволюционный анализ функциональной и структурной дифференциации бухгалтерского учета [Текст] / Л.В. Перекрестова // Бухгалтерский учет. - 2001. - №7. 